\title{
Economic Evaluation of Dexmedetomidine Relative to Midazolam for Sedation in the Intensive Care Unit
}

\author{
Jean Lachaine and Catherine Beauchemin
}

\begin{abstract}
Background: Dexmedetomidine is an $\alpha_{2}$-receptor agonist administered by continuous infusion in the intensive care unit (ICU) for sedation of critically ill patients who are undergoing mechanical ventilation following intubation. Relative to ICU patients receiving midazolam (a $\gamma$-aminobutyric acid agonist) for sedation, those receiving dexmedetomidine spent less time on ventilation, had fewer episodes of delirium, and had a lower incidence of tachycardia and hypertension.
\end{abstract}

Objective: To assess the economic impact, in a Canadian context, of dexmedetomidine, relative to midazolam, for sedation in the ICU.

Methods: This economic evaluation was based on a cost-consequences analysis, from the perspective of the Canadian health care system. The selected time horizon was an ICU stay (maximum 30 days). Clinical data were obtained from a previously published prospective, randomized, double-blind trial comparing dexmedetomidine and midazolam. This evaluation considered the costs of the medications, mechanical ventilation, and delirium episodes, as well as costs associated with adverse events requiring an intervention. All costs were adjusted to 2010 and are reported in Canadian dollars.

Results: The average cost of the medication was higher for dexmedetomidine than midazolam ( $\$ 1929.57$ versus $\$ 180.10$ per patient), but the average costs associated with mechanical ventilation and management of delirium were lower with dexmedetomidine than with midazolam (\$2939 versus \$4448 for ventilation; \$2127 versus \$3012 for delirium). The overall cost per patient was lower with dexmedetomidine than with midazolam (\$7022 versus $\$ 7680$ ). Deterministic sensitivity analysis confirmed the robustness of the difference.

Conclusions: The use of dexmedetomidine was, in most contexts, a more favourable strategy than the use of midazolam, in terms of clinical consequences and economic impact. Dexmedetomidine was less expensive than midazolam and was associated with lower occurrence of delirium and shorter duration of mechanical ventilation.

Key words: dexmedetomidine, sedation, intensive care unit, economic evaluation

Can J Hosp Pharm 2012;65(2):103-110

\section{RÉSUMÉ}

Contexte : La dexmédétomidine est un agoniste des récepteurs alpha-2 adrénergiques qu'on administre par perfusion continue à l'unité de soins intensifs (USI) pour la sédation des patients en phase critique, mis sous ventilation artificielle après intubation. Par rapport aux patients de l'USI qui ont reçu du midazolam (un agoniste de l'acide gammaaminobutyrique) comme sédatif, ceux qui ont reçu de la dexmédétomidine sont restés moins longtemps sous ventilation, ont éprouvé moins d'épisodes de délire et ont connu une incidence plus faible de tachycardie et d'hypertension.

Objectif : Comparer les coûts de l'emploi de la dexmédétomidine à ceux du midazolam pour la sédation des patients d'une USI dans un contexte canadien.

Méthodes : Une évaluation économique fondée sur une analyse coûts-conséquences a été menée dans le contexte du système de soins de santé canadien. La période d'évaluation retenue a été un séjour à l'USI d'un maximum de 30 jours. Les données cliniques ont été tirées des résultats publiés d'un essai prospectif, à répartition aléatoire et à double insu comparant la dexmédétomidine et le midazolam. Les coûts pris en compte dans cette évaluation étaient ceux des médicaments, de la ventilation artificielle, des épisodes de délire de même que ceux associés aux événements indésirables nécessitant une intervention. Tous les coûts ont été convertis en dollars de 2010 et sont présentés en dollars canadiens.

Résultats : Le coût moyen des médicaments était plus élevé pour la dexmédétomidine que pour le midazolam $(1929,57$ \$ contre $180,10 \$$ par patient), mais les coûts moyens associés à la ventilation artificielle et à la prise en charge du délire étaient moins élevés avec la dexmédétomidine qu'avec le midazolam (2939 \$ contre 4448 \$ pour la ventilation; 2127 \$ contre $3012 \$$ pour le délire). Le coût global par patient était inférieur avec la dexmédétomidine qu’avec le midazolam (7022 \$ contre 7680 \$). Une analyse de sensibilité déterministe a confirmé la robustesse de cette différence.

Conclusions : L'emploi de la dexmédétomidine était dans la plupart des cas une stratégie préférable à l'emploi du midazolam, pour ce qui est des conséquences cliniques et de la résultante financière. La dexmédétomidine s'est révélée moins chère que le midazolam et a été associée à une fréquence moindre de délire et à une durée moindre de la ventilation artificielle.

Mots clés : dexmédétomidine, sédation, unité de soins intensifs, évaluation économique

[Traduction par l'éditeur] 


\section{INTRODUCTION}

$\mathrm{L}$ ife-saving treatments such as mechanical ventilation, dialysis, and use of central venous catheters administered in the intensive care unit (ICU) often require sedation and analgesia to help the healing process, to facilitate use of lifesupport technology, and to relieve anxiety and pain. Previous studies have shown that strategies for sedation, such as provision of analgesia before sedation according to specific protocols, use of a scoring system for both sedation and delirium (to help recognize serious adverse effects associated with the medications administered), and effective monitoring of pain and delirium, have potential effects on patient outcomes and therefore on utilization of health care resources..$^{1-3}$

Currently, 2 classes of medications are commonly used for sedation: $\gamma$-aminobutyric acid (GABA) agonists, such as midazolam, lorazepam, and propofol; and $\alpha_{2}$-agonists, such as clonidine and dexmedetomidine. In Canada, midazolam and propofol are the most common sedatives, ${ }^{4}$ whereas in the United States, midazolam, lorazepam, and propofol tend to be used most frequently. ${ }^{5}$ GABA agonists generally cause prolonged sedation and are known to interact with other medications and to cause serious adverse events such as hypotension and respiratory depression. Because $\alpha_{2}$-agonists provide analgesia and sedation with little or no respiratory depression, they represent an interesting alternative to GABA agonists. The choice between these 2 drug classes also influences the occurrence of delirium, the duration of mechanical ventilation, the length of the ICU stay, and, consequently, health care costs. ${ }^{3}$

Precedex (dexmedetomidine; Hospira Canada) received its notice of compliance from Health Canada on December 9, 2009. ${ }^{6}$ Dexmedetomidine is administered by continuous infusion for sedation of critically ill ICU patients who have undergone intubation and are receiving mechanical ventilation. Clinical trials have already demonstrated its clinical efficacy and safety. ${ }^{7.8}$ In particular, dexmedetomidine was associated with shorter duration of mechanical ventilation, fewer episodes of delirium, and lower incidences of tachycardia and hypertension, relative to midazolam, but a higher incidence of bradycardia. ${ }^{8}$ Recently, a cost-minimization analysis conducted in the United States compared dexmedetomidine with midazolam for long-term sedation in the ICU.' The objective of that study was to compare dexmedetomidine and midazolam in terms of the costs associated with administration to patients undergoing mechanical ventilation in the ICU and to identify the factors influencing these costs. The analysis took into account all costs incurred during the ICU stay, including costs associated with ICU care and mechanical ventilation, administration of the study drug, and treatment of adverse effects. Including drug acquisition cost, sedation with dexmedetomidine was much less expensive than sedation with midazolam.
The savings were due mainly to a shorter stay in the ICU and lower costs of mechanical ventilation. However, until now, no economic evaluation has estimated the economic impact of dexmedetomidine from a Canadian perspective.

In the current Canadian context, there is enormous variability in clinicians' sedation practices, not only in terms of choice of drugs but also in the use of standard protocols for and monitoring of sedation. ${ }^{10}$ Given the magnitude of potential savings associated with choice of treatment and the possible need to standardize sedation practices throughout Canada, it is even more relevant to consider the economic benefits that could result from using dexmedetomidine instead of other sedatives that are commonly used in Canada, such as midazolam and propofol.

The objective of this cost-consequences evaluation was to compare dexmedetomidine and midazolam in terms of the costs associated with administration of these drugs in critically ill patients in Canadian ICUs, with consideration of their respective efficacy and safety.

\section{METHODS}

\section{Study Design}

To assess the economic impact of dexmedetomidine for sedation in the ICU, relative to midazolam, this economic evaluation was based on a cost-consequences analysis. The analysis was performed in accordance with the latest guidelines for economic evaluation of health technologies developed in Canada, as recommended by the Canadian Agency for Drugs and Technology in Health (CADTH). ${ }^{11}$ Midazolam was chosen as the comparator to allow use of data from the clinical evaluation performed by Riker and others, ${ }^{8}$ but also because this agent is widely used in Canada for the sedation of ICU patients and because it represents a relatively inexpensive treatment choice.

A cost-consequences analysis is usually not a preferred method for economic evaluation. However, in this case, it was deemed to be the most appropriate for highlighting the features that differentiate dexmedetomidine and midazolam both clinically and economically, according to the results of the Safety and Efficacy of Dexmedetomidine COmpared with Midazolam (SEDCOM) study. ${ }^{8}$ Those results indicated no difference between dexmedetomidine and midazolam in terms of time to achieve the targeted sedation level in mechanically ventilated patients in the ICU. However, at comparable sedation levels, patients treated with dexmedetomidine spent less time on mechanical ventilation and experienced less delirium, and there was a lower incidence of tachycardia and hypertension. Since there is no clinical evidence supporting a difference in efficacy between these 2 treatments, a cost-effectiveness analysis or a cost-utility analysis would not be appropriate. Moreover, although control of sedation and avoidance of delirium have a 
positive impact on quality of life, these effects occur only for relatively short periods of time. Consequently, estimation of quality-adjusted life-years (QALYs) resulting from this intervention would be inadequate. Indeed, Bala and Zarkin ${ }^{12}$ used the dentistry example of local anesthesia for a root canal procedure to demonstrate that QALYs are not applicable for assessing short-term health states. Moreover, given that the 2 treatments being compared in the current study differ in terms of duration of mechanical ventilation and incidence of adverse events, it would be inappropriate to perform a cost-minimization analysis, which requires equivalence of treatments.

This economic evaluation was performed from the perspective of the Canadian health care system. An analysis from the societal perspective would also have been of interest, but available data did not allow us to identify differences between treatments that would affect costs incurred outside the health system, such as costs borne by the patient or the patient's family or costs associated with productivity losses.

\section{Clinical Input and Outcome Measures}

The clinical data for this economic evaluation were drawn from the SEDCOM study, which was undertaken to compare dexmedetomidine and midazolam in terms of the efficacy and safety of prolonged sedation induced by these 2 agents in patients undergoing mechanical ventilation. The SEDCOM study was a prospective randomized, double-blind trial conducted in 68 centres in 5 countries between March 2005 and August 2007. The study enrolled 375 patients in medical or surgical ICUs for whom mechanical ventilation and sedation for a period of 3 days or more were anticipated. The patients had no significant concurrent disease.

The level of sedation was assessed with the Richmond Agitation-Sedation Scale (RASS), ${ }^{13}$ and the level of delirium was assessed with the Confusion Assessment Method for the ICU (CAM-ICU). ${ }^{14}$

Dexmedetomidine $(0.2-1.4 \mathrm{mg} / \mathrm{kg}$ per hour) was administered to 244 patients and midazolam $(0.02-0.1 \mathrm{mg} / \mathrm{kg}$ per hour) was administered to 122 patients to achieve light sedation (RASS score between -2 and +1 ). The drug was given from the date of each patient's recruitment until extubation or for a maximum of 30 days. The average duration of dexmedetomidine administration in the SEDCOM study was 3.5 days, whereas the Canadian product monograph indicates that dexmedetomidine infusion should not exceed 24 h. ${ }^{15}$ The primary outcome was the percentage of time that each patient spent within the target RASS range. Secondary outcomes were the prevalence and duration of delirium, the use of fentanyl and open-label midazolam, and nursing assessments. Other outcomes, such as duration of mechanical ventilation, length of stay in the ICU, and incidence of adverse events, were also considered. All outcome measures were defined within a time horizon corresponding to a maximum ICU stay of 30 days.

According to the results of the SEDCOM study, ${ }^{8}$ there was no significant difference between treatment arms in terms of the percentage of time spent within the target RASS range. However, the prevalence of delirium episodes was lower and the median time to extubation was shorter among patients treated with dexmedetomidine. Time in the ICU was shorter with dexmedetomidine than with midazolam, but this difference did not reach statistical significance. Bradycardia was more likely to develop in patients treated with dexmedetomidine (42.2\% versus $18.9 \% ; p<0.001)$, but the difference in the proportion of patients requiring additional intervention was not significant. As well, there was a lower tendency for development of tachycardia and hypertension requiring treatment among patients treated with dexmedetomidine.

\section{Costs}

The following costs were considered in this analysis: costs associated with the sedatives (dexmedetomidine and midazolam), costs of open-label treatment involving additional administration of midazolam, costs of an ICU stay with mechanical ventilation, and costs associated with adverse events. The cost of an ICU stay with mechanical ventilation was derived from the fully allocated accounting system of St Paul's Hospital in Vancouver, British Columbia, as reported by Anis and others. ${ }^{16}$ The cost associated with episodes of delirium (one of the adverse events) was adapted for Canada from a US study that specifically focused on extra costs incurred by the occurrence of delirium. ${ }^{17}$ The cost of dexmedetomidine (Precedex) was provided by the manufacturer (Hospira Canada), and the cost of midazolam was taken from Quebec's Liste des médicaments. ${ }^{18}$ The overall cost of treatment took into account the doses administered in the SEDCOM study and the period over which treatment was administered. For adverse events necessitating intervention, the cost of medical consultation was added. Specifically, the physician's fee for care of a patient in the ICU was $\$ 130$, according to the current billing manual of the Régie de l'assurance maladie du Québec. ${ }^{19}$ All costs were adjusted to reflect the value in 2010, according to Statistics Canada's consumer price index for health care. ${ }^{20}$ However, given the short time horizon of the study, it was not necessary to discount either costs or effects.

\section{Sensitivity Analysis}

To estimate the robustness of the baseline results, deterministic sensitivity analyses were performed. These analyses took into account alternative values for the cost of an ICU stay, the cost of mechanical ventilation, and the cost of delirium episodes. 


\section{RESULTS}

\section{Efficacy of Treatment}

The outcome measures for the comparison of dexmedetomidine and midazolam, as determined in the SEDCOM study, ${ }^{8}$ are reported in Table 1 . There was no significant difference between the 2 drugs in terms of the percentage of time in the target sedation range or duration of the ICU stay. However, the duration of mechanical ventilation was significantly longer with midazolam, and higher proportions of the patients receiving midazolam had delirium and hypertension episodes requiring intervention. Also, fewer patients treated with midazolam required open-label midazolam. ${ }^{8}$

\section{Cost of Treatments and Other Health Care Resources}

All costs associated with sedation with dexmedetomidine and midazolam, in addition to the costs associated with additional outcomes, are reported in Table 2. Taking into account the dose of each drug administered and the duration of administration, the estimated cost was significantly higher for dexmedetomidine than for midazolam. For some patients, adjunct therapy with additional doses of midazolam was needed. The average per-patient cost of this additional treatment, estimated on the basis of the proportion of patients for whom this additional therapy was required and the median dose used, was minimal.

Additional outcomes included the duration of mechanical ventilation, the length of stay in the ICU, and adverse effects. The cost of an ICU stay could be found for only one Canadian institution, specifically the estimate based on the fully allocated accounting system of St Paul's Hospital in Vancouver, British Columbia (the St Paul's Hospital Cost Model), reported by Anis and others. ${ }^{16}$ Dasta and others ${ }^{9}$ estimated that the average daily costs of mechanical ventilation represented $31.9 \%$ of the overall daily cost of intensive care. This proportion was applied to the average daily cost of ICU care in Canada to estimate the daily cost of mechanical ventilation. Given that patients treated with dexmedetomidine and midazolam required 3.7 and 5.6 days of mechanical ventilation in the ICU, respectively, the costs associated with mechanical ventilation were estimated as \$2939 and \$4448, respectively (Table 2).

The costs associated with delirium episodes were estimated using data collected by Milbrandt and others, ${ }^{17}$ who found that delirium was associated with a 39\% (95\% confidence interval [CI] 12\%-72\%) increase in the cost of ICU care. To estimate the cost associated with delirium per Canadian patient, this $39 \%$ increase was adjusted to take into account the fact that average ICU costs already include the costs for patients both with and without delirium. According to the recent Delirium Epidemiology in Critical Care (DECCA) study by Salluh and others ${ }^{21}$ the percentage of ICU patients with delirium was $32.3 \%$. On the basis of this adjustment, the 39\% increase reported by Milbrandt and others ${ }^{17}$ corresponds to a $23.4 \%$ increase for Canadian patients (adjusted 95\% CI 7.8\%-39.5\%). Because the lengths of stay in the ICU were not statistically different between the 2 groups, the average of the 2 group means was used as a conservative estimate of overall mean length of stay. The proportion of patients experiencing delirium was smaller in the dexmedetomidine group than in the midazolam group $(54.1 \%$ and $76.6 \%$, respectively), and the average costs per patient associated with delirium were therefore calculated as $\$ 2127$ and $\$ 3012$, respectively (Table 2).

In each treatment arm, some patients experienced adverse events, such as hypotension, bradycardia, tachycardia, and hypertension. Some of these adverse events required specific interventions, which resulted in additional costs. However, hypertension was the only adverse effect for which the percentage of patients requiring intervention differed significantly between the 2 groups ( $p=0.02$; see Table 1 ). The exact cost of interventions for hypertension could not be estimated. Therefore, the cost of one medical consultation was added for each case of hypertension requiring intervention, which resulted in an average per-patient cost associated with hypertension of $\$ 24.57$ for dexmedetomidine and $\$ 38.35$ for midazolam (Table 2).

\section{Summary of Cost-Consequences Analysis}

All costs and effects for which there was a statistically significant difference between the 2 treatments are reported in

Table 1. Efficacy and Safety of Treatment with Dexmedetomidine and Midazolam*

\begin{tabular}{|c|c|c|c|}
\hline Outcome & $\begin{array}{l}\text { Dexmedetomidine } \\
\quad(n=244)\end{array}$ & $\begin{array}{l}\text { Midazolam } \\
(n=122)\end{array}$ & $p$ value \\
\hline Time within target RASS range (mean \%) & 77.3 & 75.1 & 0.18 \\
\hline Duration of mechanical ventilation (days) (median and 95\% Cl) & $3.7(3.1-4.0)$ & $5.6(4.6-5.9)$ & 0.01 \\
\hline Duration of ICU stay (days) (median and $95 \% \mathrm{CI}$ ) & $5.9(5.7-7.0)$ & $7.6(6.7-8.6)$ & 0.24 \\
\hline$\%$ of patients with delirium episodes & 54.1 & 76.6 & $<0.001$ \\
\hline$\%$ of patients requiring open-label midazolam & 62.7 & 49.2 & 0.02 \\
\hline$\%$ of patients with hypertension episodes requiring intervention & 18.9 & 29.5 & 0.02 \\
\hline
\end{tabular}

$\overline{\mathrm{Cl}}=$ confidence interval, ICU = intensive care unit, RASS = Richmond Agitation-Sedation Study.

*Data from the SEDCOM study. ${ }^{8}$ 
Table 2. Calculation of Costs Associated with Sedation with Dexmedetomidine and Midazolam

\begin{tabular}{|c|c|c|}
\hline Cost Element & Dexmedetomidine & Midazolam \\
\hline \multicolumn{3}{|l|}{ Administration of sedative } \\
\hline Cost of medication & $\$ 0.3145 / \mu \mathrm{g}$ & $\$ 0.3714 / \mathrm{mg}$ \\
\hline Hourly dose & $0.83 \mu \mathrm{g} / \mathrm{kg}$ & $0.056 \mathrm{mg} / \mathrm{kg}$ \\
\hline Mean body weight per patient & $88 \mathrm{~kg}$ & $88 \mathrm{~kg}$ \\
\hline Mean duration of administration & 3.5 days & 4.1 days \\
\hline Per-patient cost of treatment & $\$ 1929.57$ & $\$ 180.10$ \\
\hline \multicolumn{3}{|l|}{ Open-label treatment with midazolam } \\
\hline Cost of medication (midazolam) & $\$ 0.3714 / \mathrm{mg}$ & $\$ 0.3714 / \mathrm{mg}$ \\
\hline Dose administered & $0.09 \mathrm{mg} / \mathrm{kg}$ & $0.11 \mathrm{mg} / \mathrm{kg}$ \\
\hline Mean body weight per patient & $88 \mathrm{~kg}$ & $88 \mathrm{~kg}$ \\
\hline Proportion of patients requiring additional therapy & $63 \%$ & $49 \%$ \\
\hline Mean per-patient cost of additional therapy & $\$ 1.85$ & $\$ 1.76$ \\
\hline \multicolumn{3}{|l|}{ Mechanical ventilation } \\
\hline Daily Canadian cost of ICU care* & $\$ 1965 /$ day & $\$ 1965 /$ day \\
\hline Adjustment to 2010 dollarst & $\$ 2490 /$ day & $\$ 2490 /$ day \\
\hline Proportion of ICU cost for mechanical ventilation ${ }^{9}$ & $31.9 \%$ & $31.9 \%$ \\
\hline Daily cost for mechanical ventilation & $\$ 794 /$ day & $\$ 794 /$ day \\
\hline Duration of mechanical ventilation & 3.7 days & 5.6 days \\
\hline Mean per-patient cost of mechanical ventilation & $\$ 2939$ & $\$ 4448$ \\
\hline \multicolumn{3}{|l|}{ Delirium episodes } \\
\hline Daily Canadian cost of ICU care (2010 dollars) & $\$ 2490$ & $\$ 2490$ \\
\hline Mean length of ICU stay $¥$ & 6.75 days & 6.75 days \\
\hline Total cost of ICU stay & $\$ 16808$ & $\$ 16808$ \\
\hline$\%$ of ICU cost associated with delirium§ & $23.4 \%$ & $23.4 \%$ \\
\hline Cost associated with delirium & $\$ 3933$ & $\$ 3933$ \\
\hline Proportion of patients experiencing delirium & $54.1 \%$ & $76.6 \%$ \\
\hline Mean per-patient cost associated with delirium & $\$ 2127$ & $\$ 3012$ \\
\hline \multicolumn{3}{|l|}{ Hypertension episodes requiring intervention } \\
\hline Professional fee & $\$ 130$ & $\$ 130$ \\
\hline Proportion of patients with hypertension requiring intervention & $18.9 \%$ & $29.5 \%$ \\
\hline Mean per-patient cost associated with hypertension & $\$ 24.57$ & $\$ 38.35$ \\
\hline
\end{tabular}

$\mathrm{ICU}=$ intensive care unit.

*Based on St Paul's Hospital Cost Model (1997). ${ }^{16}$

tConversion from 1997 to 2010, based on consumer price index for health care ${ }^{20}(2010 / 1997=115.3 / 91=1.267)$.

¥Mean length of stay in the ICU was not statistically different between the 2 groups (see Table 2). Therefore, the average of the group means was used as a conservative estimate of overall mean length of stay in the ICU.

§The 39\% increase in ICU costs associated with delirium, as reported by Milbrandt and others, ${ }^{17}$ was adjusted to take into account the fact that the average ICU cost accounts for the $32.3 \%$ of ICU patients who experience delirium. ${ }^{21}$

\section{Table 3. Summary of Cost-Consequences Analysis*}

Drug Used; Cost of Item

\begin{tabular}{lcrr}
\cline { 2 - 3 } Item & Dexmedetomidine & Midazolam & Difference \\
\hline Medication & $\$ 1929.57$ & $\$ 180.10$ & $\$ 1749.47$ \\
Additional treatment & $\$ 1.85$ & $\$ 1.76$ & $\$ 0.09$ \\
Mechanical ventilation & $\$ 2938.62$ & $\$ 4447.64$ & $-\$ 1509.02$ \\
Associated with delirium & $\$ 2127.49$ & $\$ 3012.30$ & $-\$ 884.81$ \\
Adverse events & $\$ 24.57$ & $\$ 38.35$ & $-\$ 13.78$ \\
Total per-patient cost & $\$ 7022.10$ & $\$ 7680.15$ & $-\$ 658.05$
\end{tabular}

*Data provided only for costs and effects with a statistically significant difference between dexmedetomidine and midazolam. 
Table 3. In the dexmedetomidine treatment group, delirium occurred in fewer patients (difference of 22.5 percentage points), duration of mechanical ventilation was shorter (by 1.9 days), open-label midazolam treatment was required for more patients (difference of 13.5 percentage points), and intervention for hypertension was required for fewer patients (difference of 10.6 percentage points). As a result, the total per-patient cost of dexmedetomidine administration was $\$ 7022, \$ 658$ less than the total per-patient cost of midazolam administration (\$7680).

\section{Sensitivity Analysis}

Sensitivity analyses were performed to take into account the uncertainties associated with the costs of ICU care, mechanical ventilation, and delirium. For time to extubation (i.e., duration of mechanical ventilation), worst-case and bestcase scenarios, based on the confidence limits for time to extubation for dexmedetomidine and midazolam, were developed. The daily cost of ICU care was arbitrarily subjected to changes of $+25 \%$ and $-25 \%$, as no confidence interval was available for this parameter. The cost of delirium was first subjected to the value of the confidence interval reported by Milbrandt and others ${ }^{17}$ in terms of the adjusted increase in ICU cost based on the DECCA study ${ }^{21}$ (12\% [adjusted value 7.8\%] to $72 \%$ [adjusted value $39.5 \%$ ]). Likewise, the difference in the percentage of patients with delirium (a difference of 22.5 percentage points) was explored using the values of the confidence interval of this difference (14 to 33 percentage points). Finally, sensitivity analyses were performed for the worst-case and base-case scenarios combining these 2 parameters (i.e., 7.8\% increased cost with difference of 14 percentage points and $39.5 \%$ increased cost with difference of 33 percentage points).

The results of all sensitivity analyses favoured dexmedetomidine, except when the highest value for time to extubation with dexmedetomidine and the lowest value for time to extubation with midazolam were used (Table 4).

\section{DISCUSSION}

The results of a previous cost-minimization analysis performed in the United States indicated that dexmedetomidine was less costly than midazolam for long-term sedation in the ICU.? The results of the cost-consequences analysis reported here, which was performed from a Canadian perspective, lead to the same conclusion. Compared with midazolam, dexmedetomidine was associated with a lower incidence of delirium episodes and a shorter median time to extubation, ${ }^{8}$ while being a cost-saving alternative. The primary drivers of cost savings in both the cost-minimization study ${ }^{9}$ and the cost-consequences study were reduced costs associated with the ICU stay and reduced costs of mechanical ventilation.

The costs associated with ICU care are recognized to be substantial, but they have seldom been estimated. For the purpose of this economic evaluation, we relied on an average daily cost for an ICU stay, based on the fully allocated accounting system of St Paul's Hospital in Vancouver. No other valid source for the cost of ICU care in Canada could be found. As well, the costs associated with mechanical ventilation and delirium have never been directly estimated in Canada, but their contribution to overall ICU cost has been estimated in US studies, and this

\section{Table 4. Results of Deterministic Sensitivity Analysis}

Drug Used; Total Per-Patient Cost*

\begin{tabular}{|c|c|c|c|}
\hline \multirow{2}{*}{ Item } & & \multirow[b]{2}{*}{ Difference } \\
\hline & Dexmedetomidine & Midazolam & \\
\hline Baseline & $\$ 7022$ & $\$ 7680$ & $-\$ 658$ \\
\hline \multicolumn{4}{|l|}{ Time to extubation } \\
\hline Worst case (4.0 vs. 4.6$)$ & $\$ 7256$ & $\$ 6886$ & $\$ 370$ \\
\hline Best case (3.1 vs. 5.9) & $\$ 6542$ & $\$ 7918$ & $-\$ 1376$ \\
\hline \multicolumn{4}{|l|}{ Average daily cost of ICU } \\
\hline Minus 25\% & $\$ 6487$ & $\$ 6927$ & $-\$ 440$ \\
\hline Plus 25\% & $\$ 7549$ & $\$ 8433$ & $-\$ 884$ \\
\hline \multicolumn{4}{|l|}{ Cost of delirium } \\
\hline $7.8 \%$ of ICU cost & $\$ 5602$ & $\$ 5672$ & $-\$ 70$ \\
\hline $39.5 \%$ of ICU cost & $\$ 8479$ & $\$ 9753$ & $-\$ 1274$ \\
\hline \multicolumn{4}{|l|}{ Difference in delirium } \\
\hline 14 percentage points & $\$ 7187$ & $\$ 7511$ & $-\$ 324$ \\
\hline 33 percentage points & $\$ 6802$ & $\$ 7874$ & $-\$ 1072$ \\
\hline $\begin{array}{l}\text { Delirium worst case: cost } 7.8 \% \text { of ICU cost and } \\
\text { difference of } 14 \text { percentage points }\end{array}$ & $\$ 5659$ & $\$ 5616$ & $\$ 43$ \\
\hline $\begin{array}{l}\text { Delirium best case: cost } 39.5 \% \text { of ICU cost and } \\
\text { difference of } 33 \text { percentage points }\end{array}$ & $\$ 8114$ & $\$ 10078$ & $-\$ 1964$ \\
\hline
\end{tabular}

*Based on costs and effects with a statistically significant difference between dexmedetomidine and midazolam, as presented in Table 3. 
information was used to determine their costs in the Canadian context. To estimate the robustness of the results, sensitivity analyses were performed for the main cost drivers of this economic evaluation. In most cases, the results of the sensitivity analysis indicated that dexmedetomidine was a costsaving alternative to midazolam, except when the worst-case scenarios for time to intubation and for delirium were examined. In fact, optimizing sedation and analgesia in the ICU for critically ill patients may decrease the length of the ICU stay or reduce the duration of mechanical ventilation, which may significantly reduce the high costs of ICU care.

Until now, no other study has compared the economic impacts of dexmedetomidine and midazolam for sedation in the ICU in a Canadian context. However, a Canadian randomized multicentre study demonstrated that use of propofol reduced the time to extubation relative to midazolam and was associated with a potential cost saving, although there was no difference in the intensity of resource use or ICU length of stay. ${ }^{16}$

The results of this economic evaluation are based on the efficacy and safety results of the SEDCOM study. ${ }^{8}$ That study incorporated best sedation practices (light-to-moderate sedation level and daily assessments of arousal in both study groups) and was the first to demonstrate that using dexmedetomidine for prolonged sedation of patients in the ICU provides several advantages over midazolam. Since the economic evaluation was based on the SEDCOM study, some limitations of the current study are similar to those reported by the SEDCOM investigators. ${ }^{8}$ For example, although midazolam is widely used for long-term sedation in Canada, other sedatives, such as propofol, are also commonly used but were not compared with dexmedetomidine in the current study. However, in a smaller randomized study comparing dexmedetomidine with propofol, the reported incidence of delirium was 3\% with dexmedetomidine and 50\% with propofol..$^{22}$ In the current economic evaluation, it was assumed that dexmedetomidine and midazolam were equivalent in terms of the time to achieve targeted sedation. However, the SEDCOM trial was not a non-inferiority trial, so even if the 2 products had the same time to achieve targeted sedation, it is not absolutely certain that they are equivalent.

Cost-consequences analyses usually provide information to decision-makers in a transparent and disaggregated format, which allows them to decide the impact of each outcome individually. One problem with this type of analysis is that the weighting of the relative importance of different costs and benefits is left to the individual decision-maker, which can hinder making a decision that should be as objective as possible. ${ }^{23}$ This is particularly true when the results do not all point in the same direction. In the current study, all of the outcomes considered were favourable to dexmedetomidine, which would facilitate decision-making. Moreover, for completeness, this cost-consequences analysis took into account all of the clinical outcomes with significant differences between dexmedetomidine and midazolam (i.e., duration of mechanical ventilation and proportions of patients who had episodes of delirium, who required open-label midazolam therapy, and who had episodes of hypertension requiring intervention).

\section{CONCLUSIONS}

The results of this cost-consequences analysis indicate that the use of dexmedetomidine is a more favourable strategy for sedation than use of midazolam, in most ICU contexts. In fact, although the initial cost of dexmedetomidine is higher than that of midazolam, the savings realized in terms of reductions in duration of mechanical ventilation and in occurrence of delirium episodes make it a less expensive option overall.

\section{References}

1. Chernik DA, Gillings D, Laine H, Hendler J, Silver JM, Davidson AB, et al. Validity and reliability of the Observer's Assessment of Alertness/ Sedation Scale: study with intravenous midazolam. J Clin Psychopharmacol 1990;10(4):244-251.

2. Jacobi J, Fraser GL, Coursin DB, Riker RR, Fontaine D, Wittbrodt ET, et al. Clinical practice guidelines for the sustained use of sedatives and analgesics in the critically ill adult. Crit Care Med 2002;30(1):119-141.

3. Ely EW, Siegel MD, Inouye SK. Delirium in the intensive care unit: an under-recognized syndrome of organ dysfunction. Semin Respir Crit Care Med 2001;22(2):115-126.

4. Burry L, Perreault M, Williamson D, Cook D, Wong S, Rodrigues H, et al. A prosopective evaluation of sedative, analgesic, anti-psychotic and paralytic practices in Canadian mechanically ventilated adults [abstract]. Am J Respir Crit Care Med 2009;79:A5492.

5. Riker RR, Fraser GL. Altering intensive care sedation paradigms to improve patient outcomes. Crit Care Clin 2009;25(3):527-538, viii-ix.

6. Precedex. In: Notice of Compliance online query [database]. Ottawa (ON): Health Canada; 2009 Dec 9 [cited 2012 Apr 2]. Available from: http://webprod3.hc-sc.gc.ca/noc-ac/index-eng.jsp [search for brand name "Precedex"].

7. Herr DL, Sum-Ping ST, England M. ICU sedation after coronary artery bypass graft surgery: dexmedetomidine-based versus propofol-based sedation regimens. J Cardiothorac Vasc Anesth 2003;17(5):576-584.

8. Riker RR, Shehabi Y, Bokesch PM, Ceraso D, Wisemandle W, Koura F, et al. Dexmedetomidine vs midazolam for sedation of critically ill patients: a randomized trial. JAMA 2009;301(5):489-499.

9. Dasta JF, Kane-Gill SL, Pencina M, Shehabi Y, Bokesch PM, Wisemandle $\mathrm{W}$, et al. A cost-minimization analysis of dexmedetomidine compared with midazolam for long-term sedation in the intensive care unit. Crit Care Med 2010;38(2):497-503.

10. Mehta S, Burry L, Fischer S, Martinez-Motta JC, Hallett D, Bowman D, et al. Canadian survey of the use of sedatives, analgesics, and neuromuscular blocking agents in critically ill patients. Crit Care Med 2006;34(2):374-380.

11. Lignes directrices de l'évaluation économique des technologies de la santé au Canada. 3rd edition. Ottawa (ON): Canadian Agency for Drugs and Technology in Health; 2006.

12. Bala MV, Zarkin GA. Are QALYs an appropriate measure for valuing morbidity in acute diseases? Health Econ 2000;9(2):177-180.

13. Sessler CN, Gosnell MS, Grap MJ, Brophy GM, O’Neal PV, Keane KA, et al. The Richmond Agitation-Sedation Scale: validity and reliability in adult intensive care unit patients. Am J Respir Crit Care Med 2002;166(10):1338-1344.

14. Ely EW, Inouye SK, Bernard GR, Gordon S, Francis J, May L, et al. Delirium in mechanically ventilated patients: validity and reliability of the confusion assessment method for the intensive care unit (CAM-ICU). JAMA 2001;286(21):2703-2710. 
15. Precedex [Canadian product monograph]. Saint-Laurent (QC): Hospira Healthcare Corporation; 2009 Dec 8.

16. Anis AH, Wang XH, Leon H, Hall R. Economic evaluation of propofol for sedation of patients admitted to intensive care units. Anesthesiology 2002;96(1):196-201.

17. Milbrandt EB, Deppen S, Harrison PL, Shintani AK, Speroff T, Stiles RA, et al. Costs associated with delirium in mechanically ventilated patients. Crit Care Med 2004;32(4):955-962.

18. Liste des médicaments. Québec (QC): Régie de l'assurance maladie du Québec; 2010.

19. Manuel de facturation des médecins spécialistes. Québec (QC): Régie de l'assurance maladie du Québec; 2009.

20. Tableau 326-0021: indice des prix à la consommation, dépenses et équipement du ménage, par province. Ottawa $(\mathrm{ON})$ : Statistics Canada; 2010. Available from: www.statcan.gc.ca/tables-tableaux/sum-som/102/ cst01/econ158a-fra.htm

21. Salluh JI, Soares M, Teles JM, Ceraso D, Raimondi N, Nava VS, et al.; Delirium Epidemiology in Critical Care Study Group. Delirium epidemiology in critical care (DECCA): an international study. Crit Care 2010;14(6):R210

22. Maldonado JR, Wysong A, van der Starre PJ, Block T, Miller C, Reitz BA. Dexmedetomidine and the reduction of postoperative delirium after cardiac surgery. Psychosomatics 2009;50(3):206-217.
23. Mauskopf JA, Paul JE, Grant DM, Stergachis A. The role of costconsequence analysis in healthcare decision-making. Pharmacoeconomics $1998 ; 13(3): 277-288$

Jean Lachaine, PhD, is Associate Professor in the Faculty of Pharmacy, Université de Montréal, Montréal, Quebec.

Catherine Beauchemin, MSc, is a PhD candidate in the Faculty of Pharmacy, Université de Montréal, Montréal, Quebec.

\section{Address correspondence to:}

Dr Jean Lachaine

Faculty of Pharmacy

Université de Montréal

PO Box 6128, Station Centre-ville,

Montreal QC H3C 3J7

e-mail: jean.lachaine@umontreal.ca

\section{Acknowledgment}

This economic evaluation was funded by Hospira Canada. We thank Karine Mathurin for her assistance in writing and editing the manuscript.

\section{几 Canadian Society of Hospital Pharmacists Société canadienne des pharmaciens d'hôpitaux}

\section{Membership Year 2011/2012 (July 1, 2011 - June 30, 2012)}

Are you a current member of the Canadian Society of Hospital Pharmacists?

CSHP has celebrated 64 years of inspiration and leadership among a rapidly growing network of over 3000 pharmacy colleagues. As a member of CSHP, you will have access to resources and opportunities that will enhance your career and help impact the direction of healthcare in Canada. Your participation in CSHP 2015, an initiative challenging all pharmacists to improve patient medication outcomes and safety through advancing pharmacy practice excellence by the year 2015 , is a prime example.

For more information about CSHP, please visit us at www.cshp.ca. We invite you to reap the benefits of an affordable membership with CSHP.

Membership Enquiries: Please contact Membership Services

Bus.: (613) 736-9733 Ext. 222 Fax: (613) 736-5660 Email: membershipservices@cshp.ca 